\title{
Proportion and factors associated with Hepatitis B viremia in antiretroviral treatment naïve and experienced HIV co-infected Ghanaian patients
}

Timothy N. A. Archampong ${ }^{1,2^{*}}$, Margaret Lartey ${ }^{1,2}$, Kwamena W. Sagoe $^{3}$, Adjoa Obo-Akwa ${ }^{1}$, Ernest Kenu ${ }^{2}$, Fizza S. Gillani ${ }^{4,5}$, Hongmei Yang ${ }^{6}$, Isaac Boamah ${ }^{3}$, Timothy Flanigan ${ }^{4,5}$ and Awewura Kwara ${ }^{4,5}$

\begin{abstract}
Background: The global burden of Hepatitis B virus (HBV) and HIV co-infection is enormous. The risk of developing cirrhosis and hepatocellular cancer is associated with HBV DNA levels. The main objective of the study was to determine proportion of Hepatitis B viremia in ART-naïve and ART-experienced co-infected Ghanaian patients and factors associated with HBV viremia after at least 36 weeks of lamivudine with or without tenofovir containing ART.

Methods: Hepatitis B and HIV co-infected patients who were ART-naïve or had received at least 9 months of lamivudine-containing ART were enrolled in a cross-sectional study at Korle-Bu Teaching Hospital. Demographic and clinical data were collected and samples obtained for Hepatitis B serology, liver function tests and HBV DNA. Factors associated with viremia were determined using univariate and multivariate logistic regression analysis.

Results: Of 3108 HIV-infected patients screened, 257 (8.3\%) were HBsAg-positive, of which 235 enrolled. Overall, 152 (64.7\%) were ART-experienced and 83 (35.3\%) were ART-naïve. Eighty-nine-percent of ART-naïve and $42.1 \%$ of ART-experienced patients had HBV DNA > $20 \mathrm{IJ} / \mathrm{mL}$. In multivariate analysis of all patients, being ART-naïve (OR 10.1, $95 \% \mathrm{Cl} 4.6$ - 21.9) and elevated ALT (OR 3.7, $95 \% \mathrm{Cl} 1.8$ - 7.9) were associated with Hepatitis B viremia. In treatment experienced patients, elevated ALT (OR $4.8 \mathrm{Cl} 2.0$ - 12.1) and male sex (OR 2.1, $95 \% \mathrm{Cl} 1.0$ - 4.2) were associated with Hepatitis B viremia.

Conclusions: Majority of ART-naïve (89\%) and $42 \%$ of ART-experienced patients had detectable hepatitis B viremia $>20 \mathrm{IU} / \mathrm{mL}$. An abnormal serum ALT was significantly associated with hepatitis B viremia in HBV and HIV co-infected patients irrespective of treatment status. Baseline and on-treatment ALT may be a useful non-invasive predictor of Hepatitis B viremia in resource-constrained countries in sub-Saharan Africa where infection is endemic and viral load tests are not widely available.
\end{abstract}

Keywords: ART, HIV and HBV co-infection, Viremia, Sub-Saharan Africa

\footnotetext{
* Correspondence: tnaa@doctors.net.uk

${ }^{1}$ Department of Medicine and Therapeutics, School of Medicine and

Dentistry, College of Health Sciences, University of Ghana, Accra, Ghana

${ }^{2}$ Korle-Bu Teaching Hospital, Accra, Ghana

Full list of author information is available at the end of the article
} 


\section{Background}

Globally, it is estimated that there are 240 million persons chronically infected with HBV infection, with a majority of them living in low- and middle-income countries [1]. The prevalence of chronic HBV infection varies from $0.1-2 \%$ in industrialized countries to $5-10 \%$ in Sub-Saharan Africa [1]. An estimated 6 to $14 \%$ of HIVinfected persons worldwide are chronically infected with HBV [2], with the highest rates occurring in sub-Saharan Africa and Asia [3]. The natural history of chronic HBV is negatively affected by HIV co-infection. HBV/HIV coinfected patients have lower spontaneous HBeAg seroconversion rates, higher levels of $\mathrm{HBV}$ viremia [4], faster progression to cirrhosis and increased rate of development of HCC [5].

The risk of developing cirrhosis, hepatic decompensation and HCC is associated with HBV DNA levels [6, 7]. $\mathrm{HIV}$ viremia is also associated with progression of $\mathrm{HBV}$ infection [5]. Thus, suppression of HBV DNA and HIV RNA to undetectable levels is an important treatment goal of $\mathrm{HIV} / \mathrm{HBV}$-co-infected patients $[4,8,9]$. In treated $\mathrm{HIV} / \mathrm{HBV}$ co-infected patients, detectable $\mathrm{HBV}$ viremia has been associated with positive $\mathrm{HBeAg}$, negative anti$\mathrm{HBe}, \mathrm{HBV}$ genotype A, type and duration of ART, CD4 count $<200$ cells/mm3, detectable HIV RNA, and $<95 \%$ adherence to ART [10].

In Ghana, the reported prevalence of $\mathrm{HBV}$ ranges from 12 to $15 \%$ among blood donors [11]. At the Fevers Unit, Korle-Bu Teaching Hospital (KBTH), an earlier study of 154 HIV patients found the prevalence of HBV infection was $13 \%$ [12]. In another study in Kumasi, Ghana, the prevalence of HBV infection in a cohort of $838 \mathrm{HIV}$-infected patients was found to be $16.7 \%$ [13]. Although HIV patients are increasingly screened for HbsAg, HBV DNA testing is not routinely done in Ghana due to cost implications. Until tenofovir became available in Ghana, the recommendation was to use lamivudine (3TC)-containing ART for HBV/HIV co-infected persons. The most recent HIV treatment guidelines recommend the use of tenofovir (TDF) plus 3TC or emtricitabine in patients with $\mathrm{HBV} / \mathrm{HBV}$ co-infection [14]. The HIV treatment guidelines also recommend using $\mathrm{HBV}$ viral load (where available) and ALT for treatment initiation and monitoring. The objective of this study was to determine the proportion of HBV viremia in ART-naive and treatment-experienced HIV co-infected Ghanaian patients, and to investigate the factors associated with viremia after at least 9 months of lamivudine with or without tenofovir containing ART.

\section{Methods}

Study participants and study design

Korle-Bu Teaching Hospital has 2500 beds and is the main tertiary referral centre in Accra serving the majority of the southern half of Ghana. The Fevers Unit is the principal referral centre for infectious diseases in Southern Ghana with approximately 15,000 HIV patients under regular follow-up in the out-patient clinic and over 7000 patients on regular anti-retroviral therapy. It has an in-patient department staffed with doctors, nurses, counselors, para-clinical and laboratory staff which offers service to a wide range of patients with infectious diseases including HIV.

This study used a cross-sectional design to recruit HBVHIV co-infected patients attending the Fevers (Infectious Diseases) Unit, Korle-bu, Accra, Ghana between 2012 and 2014. Adult HIV patients attending the Fevers (Infectious Diseases) Unit during the study period (2012-2014) were screened for HBsAg using the Core HBsAg rapid test (Core Diagnostics, Birmingham, UK) following informed consent. HIV and HBsAg-positive study participants were enrolled into two groups. The treatment-naive group ( $\mathrm{t} 0)$ were HBV-HIV co-infected patients who had not initiated therapy. The treatment-experienced group (t1) were HBV-HIV co-infected patients who had been on at least 9 months of 3TC containing anti-retroviral therapy. Patients were excluded if they declined to sign a consent form for participation. Demographic and clinical data were collected from enrolled patients using standardized data collection form. Medical records were also reviewed where additional clinical and laboratory data including CD4 cell count extracted as patients did not know their most recent CD4 count. Adherence status was determined using the validated Simplified Medication Adherence Questionnaire (SMAQ) [15]. All extracted data was subsequently entered into Microsoft Access.

The Institutional Review Board (IRB) of the University of Ghana Medical School, Accra, Ghana and Lifespan Hospitals, Providence, Rhode Island reviewed and approved the study.

\section{Laboratory analysis}

Enrolled patients had blood drawn into an EDTA and serum separating tube (SST). Blood in EDTA was transported to the Virology Laboratory, Korle-Bu, on ice, centrifuged within $4 \mathrm{~h}$ of collection using EBA 20 table-top centrifuge (Hettich Zentrifugen, Tuttlingen, Germany), and plasma frozen at -80 in $~ 600 \mathrm{ul}$ aliquots. HBsAg positivity was confirmed serologically using a third generation ELISA Surase B 96 (TMB) (General Biologicals Corp, Hsinchu, Taiwan). Plasma was also tested for Hepatitis B e-antigen (HBeAg), Hepatitis B e-antibody (anti$\mathrm{HBe}$ ) using EASE BN-96 (TMB) and Hepatitis B-core antibody (anti-HBc) using ANTICORASE MB-96 (TMB) from General Biologicals, Hsinchu, Taiwan. Blood in SST was tested for liver function. Plasma HBV DNA was determined using fully automated COBAS ${ }^{\bullet}$ TaqMan $^{\circledR}$ Analyzer (Roche Diagnostics GmbH, Mannheim, Germany). The 
Table 1 Baseline characteristics of HIV/HBV co-infected patients and by antiretroviral treatment Status

\begin{tabular}{|c|c|c|c|c|c|}
\hline & & Treatment status & & & \\
\hline Characteristic & All patients $(N=235)$ & Experienced $(N=152)$ & Naïve $(N=83)$ & $P$ value $T$ test & $\begin{array}{l}P \text { value Wilcoxon } \\
\text { rank sum test }\end{array}$ \\
\hline Mean (SD) age (years) & $41.0(10.0)$ & $42.6(9.5)$ & $37.9(10.2)$ & 0.0006 & $<0.0001$ \\
\hline Mean (SD) weight (kg) & $63.1(13.4)$ & $64.9(13.1)$ & $59.6(13.2)$ & 0.0038 & 0.0082 \\
\hline Mean (SD) BMI (kg/m2) & $23.4(4.7)$ & $24.2(4.7)$ & $21.8(4.5)$ & 0.0001 & 0.0002 \\
\hline \multirow[t]{2}{*}{ Mean (SD) CD4 count (cells/uL) } & $460.7(322)$ & $513(304)$ & $363(334)$ & 0.0006 & $<0.0001$ \\
\hline & n (\%) & n (\%) & n (\%) & $P$ value Chi square & $P$ value Fisher \\
\hline Sex & & & & 0.597 & 0.677 \\
\hline Female & $139(59.1)$ & $88(57.9)$ & $51(61.5)$ & & \\
\hline Male & $96(40.9)$ & $64(42.1)$ & $32(38.6)$ & & \\
\hline Ethnicity & & & & 0.744 & 0.762 \\
\hline Akan & $109(46.8)$ & $72(47.4)$ & $37(45.7)$ & & \\
\hline Ewe & $44(18.9)$ & $29(19.1)$ & $15(18.5)$ & & \\
\hline Ga & $28(12.0)$ & $20(13.1)$ & $8(9.9)$ & & \\
\hline Other & $52(22.3)$ & $31(20.4)$ & $21(25.9)$ & & \\
\hline WHO HIV stage & & & & 0.630 & 0.619 \\
\hline 1 & $55(23.7)$ & $38(25.3)$ & $17(20.7)$ & & \\
\hline 2 & $58(25.0)$ & $36(24.0)$ & $22(26.8)$ & & \\
\hline 3 & $92(39.7)$ & $61(40.7)$ & $31(37.8)$ & & \\
\hline 4 & $27(11.6)$ & $15(10.0)$ & $12(14.6)$ & & \\
\hline HBeAg positive & $47(20.0)$ & $28(18.4)$ & $19(22.9)$ & 0.413 & 0.495 \\
\hline HBeAb positive & $188(80.0)$ & $122(80.3)$ & $66(79.5)$ & 0.891 & 1.000 \\
\hline HBeAg/eAb combination & & & & 0.622 & 0.604 \\
\hline HBeAg positive/Ab negative & $41(17.5)$ & $25(16.5)$ & $16(19.3)$ & & \\
\hline HBeAg negative/Ab positive & $182(77.5)$ & $119(78.3)$ & $63(75.9)$ & & \\
\hline HBeAg negative/Ab negative & $6(2.6)$ & $5(3.3)$ & $1(1.2)$ & & \\
\hline \multirow[t]{2}{*}{ HBclgM positive } & $5(2.1)$ & $4(2.6)$ & $1(1.2)$ & 0.469 & 0.659 \\
\hline & & Treatment status & & & \\
\hline \multirow[t]{3}{*}{ Characteristic } & All patients & Experienced & Naïve & $P$ value Chi square & $P$ value Fisher \\
\hline & $N=235(\%)$ & $(N=152)$ & $(N=83)$ & & \\
\hline & & n (\%) & n (\%) & & \\
\hline Alanine aminotransferase & & & & 0.0012 & 0.0015 \\
\hline Normal (5-40 U/L) & $169(71.9)$ & $120(79.0)$ & $49(59.0)$ & & \\
\hline Elevated $>$ ULN & $66(28.1)$ & $32(21.1)$ & $34(41.0)$ & & \\
\hline Aspartate aminotransferase & & & & 0.0005 & 0.0008 \\
\hline Normal (5-50 U/L) & $178(75.7)$ & $126(82.9)$ & $52(62.7)$ & & \\
\hline Elevated $>$ ULN & $57(24.3)$ & $26(17.1)$ & $30(36.1)$ & & \\
\hline Albumin & & & & $<0.0001$ & $<0.0001$ \\
\hline Normal (36-50) & $153(65.1)$ & $117(77.0)$ & $36(43.4)$ & & \\
\hline Low $<$ LLN & $82(34.9)$ & $35(23.0)$ & $47(56.6)$ & & \\
\hline HBV DNA (IU mL-1) & & & & $<0.0001$ & $<0.0001$ \\
\hline$<20$ & $97(41.3)$ & $88(57.9)$ & $9(10.8)$ & & \\
\hline $20-2000$ & $58(24.7)$ & $31(20.4)$ & $27(32.5)$ & & \\
\hline
\end{tabular}


Table 1 Baseline characteristics of HIV/HBV co-infected patients and by antiretroviral treatment Status (Continued)

\begin{tabular}{|c|c|c|c|}
\hline $2001-20,000$ & $14(6.0)$ & $4(2.6)$ & $10(12.1)$ \\
\hline$>20,000$ & $66(28.1)$ & $29(19.1)$ & $37(44.6)$ \\
\hline \multicolumn{4}{|l|}{ Initial ART contain } \\
\hline 3ТC & $100(42.6)$ & $100(65.8)$ & - \\
\hline $3 T C+T D F$ & $52(22.1)$ & $52(34.2)$ & - \\
\hline Duration on ART & & & - \\
\hline$<1$ year & $4(1.7)$ & $4(2.6)$ & \\
\hline $1-2$ years & $38(16.2)$ & $38(25.0)$ & - \\
\hline $2-3$ years & $21(8.9)$ & $21(13.8)$ & - \\
\hline$>3$ years & $89(37.9)$ & 89 (58.6) & - \\
\hline Ever forgotten meds? & & $36(23.7)$ & - \\
\hline Do you take meds on time? & & $16(10.5)$ & - \\
\hline Stop taking meds due to illness? & & $12(7.9)$ & - \\
\hline Forgotten meds last weekend? & & $14(9.2)$ & - \\
\hline \multicolumn{4}{|c|}{ Number of times not taken meds last week? } \\
\hline 0 & & $57(37.5)$ & \\
\hline 1 to 2 & & $10(6.6)$ & \\
\hline $3-5$ & & $6(3.9)$ & \\
\hline more than 5 & & $3(2.0)$ & \\
\hline
\end{tabular}

$B M I$ body mass index

HBeAg/Ab Hepatitis B e Antigen/Antibody

HBClgM Hepatitis B core IgM

3TC lamivudine

TDF tenofovir

ULN upper limit of normal

LLN lower limit of normal

$A R T$ anti-retroviral therapy

lower limit of detection of the Roche TaqMan assay was $20 \mathrm{IU} \mathrm{mL}-1$ and the linear range $20-170,000,000 \mathrm{IU} / \mathrm{mL}$.

\section{Statistical analysis}

Statistical analyses were performed using Software SAS 9.3 (SAS Institute Inc, Cary, NC). Bivariate analyses of association between participant factors and treatment status or HBV viremia were assessed by Student's $t$-test for continuous variables or Chi-square test for categorical variables. Logistic regression with variable selection by stepwise was used to find the joint effect of the participants (treatment status, age, gender, BMI, CD4 counts, serum ALT, AST and ALB) on HBV viremia using all the data and also using treatment-specific data, and the findings were confirmed by the Smoothly Clipped Absolute Deviation (SCAD) method [16, 17]. For all analysis, a $P$ value $<0.05$ was considered significant.

\section{Results}

Study population and baseline characteristics

During the study period, 3108 HIV-infected patients were screened for HBV with HBsAg, of which 257 patients (8.3\%) were HBsAg positive. Two hundred and thirty-five (235) patients were recruited into the study, with 22 patients either declining consent or had incomplete data. The baseline characteristics of all patients and by ART status are shown in Table 1. Overall, 152 (64.7\%) of the patients were treatment-experienced and 83 (35.3\%) were treatment-naïve. In treatment-naïve and treatment experienced patients, the median HBV DNA $\log _{10} \mathrm{IU} / \mathrm{mL}$ was 8.8 (IQR: $4.8-17.6$ ) and 2.9 (IQR: $2.1-$ 6.8) respectively. The mean (SD) duration of ART in treatment-experienced patients was 4.2 (2.7) years. Treatment-experienced and naïve patients were similar except that treatment-experienced patients were older, had higher mean weight, higher mean BMI and higher mean CD4 count Table 1. The ART-experienced patients were less likely to have serum albumin level below the lower limit of normal or AST, ALT, and HBV DNA levels above the upper limit of normal (ULN), Table 1.

Of the 152 treatment-experienced patients, 100 $(65.8 \%)$ were on ART with 3TC (3TC), while 52 had received 3TC + TDF containing ART, for at least 9 months prior to sampling (3TC+TDF). Of the $(3 \mathrm{TC}+\mathrm{TDF})$ group, $37(71.2 \%)$ were on combination therapy from the onset of treatment while $15(28.8 \%)$ had been on another 3TC containing regimen before changing to 3TC + TDF combination therapy. 
Table 2 Characteristics of antiretroviral treatment-experienced HIV/HBV Co-infected patients with undetectable HBVDNA compared to those with detectable HBV DNA

\begin{tabular}{|c|c|c|c|c|}
\hline \multirow[t]{2}{*}{ Characteristic } & HBV DNA $<20$ & HBV DNA $\geq 20$ & $P$-value $T$ test & $P$-value Wilcoxon rank sum test \\
\hline & $\mathrm{IU} / \mathrm{mL}(N=64)$ & $\mathrm{IU} / \mathrm{mL}(\mathrm{N}=88)$ & & \\
\hline Mean (SD) age (years) & $42.6(9.6)$ & $42.7(9.5)$ & 0.928 & 0.701 \\
\hline Mean (SD) weight (kg) & $65.9(13.7)$ & $63.5(12.2)$ & 0.262 & 0.326 \\
\hline Mean (SD) BMI (kg/m2) & $24.5(4.6)$ & $23.9(4.7)$ & 0.415 & 0.432 \\
\hline \multirow[t]{2}{*}{ Mean (SD) CD4 count (cells/uL) } & $539(257)$ & $478(358)$ & 0.244 & 0.157 \\
\hline & n (\%) & n (\%) & $P$ value Chi square & $P$ value Fisher \\
\hline Male sex & 30 (46.9 \%) & 34 (53.1\%) & 0.019 & 0.021 \\
\hline Ethnicity & & & 0.656 & 0.679 \\
\hline Akan & $43(59.7 \%)$ & $29(40.3 \%)$ & & \\
\hline Ewe & 14 (48.3\%) & 15 (51.7 \%) & & \\
\hline Ga & $13(65.0 \%)$ & $7(35.0 \%)$ & & \\
\hline Other & 18 (58.1\%) & 13 (41.9\%) & & \\
\hline WHO HIV stage & & & 0.086 & 0.095 \\
\hline 1 & $24(63.2 \%)$ & $14(36.8 \%)$ & & \\
\hline 2 & $21(58.3 \%)$ & 15 (41.7\%) & & \\
\hline 3 & 37 (60.7 \%) & $24(39.3 \%)$ & & \\
\hline 4 & $4(26.7 \%)$ & $11(73.3 \%)$ & & \\
\hline HBeAg positive & 0 & $28(100.0 \%)$ & $<0.0001$ & $<0.0001$ \\
\hline HBeAb positive & 85 (69.7 \%) & 37 (30.3\%) & $<0.0001$ & $<0.0001$ \\
\hline $\mathrm{HB}$ eAg/E Ab combination & & & $<0.0001$ & $<0.0001$ \\
\hline HBeAg positive/Ab negative & 0 & $25(100.0 \%)$ & & \\
\hline HBeAg negative/Ab positive & 85 (71.4\%) & 34 (28.6 \%) & & \\
\hline HBeAg negative/Ab negative & $3(60.0 \%)$ & $2(40.0 \%)$ & & \\
\hline HBeAg positive/Ab positive & 0 & $3(100.0 \%)$ & & \\
\hline HBclgM positive & 0 & $4(100.0 \%)$ & 0.0175 & 0.030 \\
\hline Alanine aminotransferase & & & 0.0001 & 0.0002 \\
\hline Normal $(5-40 \mathrm{U} / \mathrm{L})$ & 79 (65.8 \%) & 41 (34.2\%) & & \\
\hline Elevated $>$ ULN & 9 (28.1\%) & $23(71.9 \%)$ & & \\
\hline Aspartate aminotransferase & & & 0.0004 & 0.0008 \\
\hline Normal (5-50 U/L) & 81 (64.3\%) & 45 (35.7 \%) & & \\
\hline Elevated $>$ ULN & $7(26.9 \%)$ & 19 (73.1\%) & & \\
\hline \multirow[t]{2}{*}{ Characteristic } & HBV DNA $<20 I U \mathrm{~mL}-1$ & HBV DNA $\geq 20 \mathrm{IU} \mathrm{mL}-1$ & $P$ value Chi square & $P$ value Fisher \\
\hline & n (\%) & n (\%) & & \\
\hline Albumin & & & 0.096 & 0.119 \\
\hline Normal (36-50 g/L) & 72 (61.5\%) & 45 (38.5\%) & & \\
\hline Low $<$ LLN & $16(45.7 \%)$ & 19 (54.3\%) & & \\
\hline Initial ART contain & & & 0.971 & 1.000 \\
\hline $3 \mathrm{TC}(n=100)$ & 42 (42.0\%) & $58(58.0 \%)$ & & \\
\hline $3 \mathrm{TC}+\operatorname{TDF}(n=52)$ & $22(42.3 \%)$ & 30 (57.7 \%) & & \\
\hline Duration on ART & & & 0.969 & 0.972 \\
\hline$<1$ year & $3(75.0 \%)$ & $1(25.0 \%)$ & & \\
\hline $1-2$ years & 22 (57.9 \%) & 16 (42.1 \%) & & \\
\hline
\end{tabular}


Table 2 Characteristics of antiretroviral treatment-experienced HIV/HBV Co-infected patients with undetectable HBVDNA compared to those with detectable HBV DNA (Continued)

\begin{tabular}{llll}
\hline $2-3$ years & $12(57.1 \%)$ & $9(42.9 \%)$ & \\
$>3$ years & $51(57.3 \%)$ & $38(42.7 \%)$ & 0.046 \\
Ever forgotten meds? & $26(72.2 \%)$ & $10(27.8 \%)$ & 0.499 \\
Do you take meds on time? & $8(50.0 \%)$ & $8(50.0 \%)$ & 0.211 \\
Stop taking meds due to illness? & $9(75.0 \%)$ & $3(25.0 \%)$ & 0.282 \\
Forgotten meds last weekend? & $10(71.4 \%)$ & $4(28.6 \%)$ & \\
Number of times not taken meds last week? & & & \\
0 & $35(61.4 \%)$ & $22(38.6 \%)$ & \\
$1-2$ & $7(70.0 \%)$ & $3(30.0 \%)$ & \\
$3-5$ & $4(66.7 \%)$ & $2(33.3 \%)$ & $2(66.7 \%)$ \\
more than 5 & $1(33.3 \%)$ & & \\
\hline
\end{tabular}

$B M I$ body mass index

$H B e A g / A b$ Hepatitis B e Antigen/Antibody

HBclgM Hepatitis B core IgM

3TC lamivudine

TDF tenofovir

ULN upper limit of normal

LLN lower limit of normal

$A R T$ anti-retroviral therapy

In the 3TC-only group, the median duration of treatment was 4.85 years (IQR: 3.0-7.1). In the 3TC+ TDF group, median duration of treatment of patients on 3TC and TDF from the onset was 1.23 years (IQR: 1.1-1.6) while 4.87 years (IQR: $3.8-5.9$ ) in patients on another $3 \mathrm{TC}$ regimen before changing to $3 \mathrm{TC}+\mathrm{TDF}$ combination therapy.

Overall, 74 (89.2 \%) of the 83 ART-naïve and 64 (42.1\%) of the 152 ART-experienced patients had HBV DNA > $20 \mathrm{IU} / \mathrm{mL}$ (Table 1). Forty-seven (56.6 \%) of ART-naïve and $33(21.7 \%)$ of ART-experienced patients had HBV $\mathrm{DNA}>2000 \mathrm{IU} / \mathrm{mL}$.

\section{Factors associated with hepatitis B viremia}

Bivariate analysis of factors associated with viremia (HBV DNA > $20 \mathrm{IU} / \mathrm{mL}$ ) in the treatment-naïve and experienced patients are shown in Tables 2 and 3. Males were more likely to have detectable HBV DNA (>20 IU/ $\mathrm{mL}$ ) in comparison to females during ART (53\% vs $47 \%, P=0.019)$. An elevated serum AST and ALT above ULN were also more likely to be associated with detectable HBV during ART $(P=0.0004)$ and $(P=0.0001)$, respectively. In treated patients, being $\mathrm{HBeAg}$-positive and $\mathrm{HBeAb}$-negative was significantly associated with detectable HBV DNA $(P<0.0001)$. Treatment regimens $(3 \mathrm{TC})$ and $(3 \mathrm{TC}+\mathrm{TDF})$ had similar likelihood of hepatitis B DNA suppression, with undetectable Hepatitis B virus in 42.0 and $42.3 \%$ respectively $(P=0.97)$. Of the 83 treatment-naïve patients, only 9 (10.8\%) had HBV DNA $<20 \mathrm{IU} / \mathrm{mL}$.
Factors associated with viremia in multivariate analysis In multivariate analysis of all patients, naïve patients were more likely than the treatment-experienced group to have detectable HBV DNA (OR 10.1, 95 \% CI 4.6 - 21.9). Additionally, elevated serum ALT level above ULN compared with normal ALT was associated with 3.7-fold increase in likelihood of detectable HBV DNA (OR 3.7, 95 \% CI 1.8 7.9). Among the treatment-experienced patients, elevated serum ALT level above ULN compared with normal ALT (OR 4.8, CI 2.1-12.1) and Male sex compared Female (OR $2.1,95 \%$ CI 1.0 - 4.2) were more likely to have detectable HBV DNA (Table 4). Multivariate analysis of treatmentnaïve patients did not yield any significant results due to small sample size.

\section{Discussion}

In this cross-sectional study, we found the prevalence of detectable $\mathrm{HBV}$ DNA $\geq 20 \mathrm{IU} / \mathrm{mL}$ in HIV-infected patients who were HBsAg positive to be $89.1 \%$ in ART-naïve and $42.1 \%$ in patients on lamivudine containing therapy with or without tenofovir for an average duration of 4.2 years (range, 9 months to 10.4 years). In all patients, ART status and serum ALT level above ULN were associated with HBV viremia. Among the treatment-experienced patients, male sex and ALT level above ULN were associated with Hepatitis $B$ viremia in both univariate and multivariate analysis. Earlier guidelines recommend that HBV DNA be fully suppressed by 12 months of TDF-based therapy in Hepatitis B-HIV infected patients $[8,18]$. However, 
Table 3 Characteristics of antiretroviral treatment-naive HIV/HBV Co-infected patients with undetectable HBVDNA compared to those with detectable HBV DNA

\begin{tabular}{|c|c|c|c|c|}
\hline \multirow[t]{2}{*}{ Characteristic } & $\mathrm{HBV}$ DNA $<20 \mathrm{IU} / \mathrm{mL}$ & $\mathrm{HBV} D \mathrm{DNA} \geq 20 \mathrm{IU} / \mathrm{mL}$ & $P$-value $T$ test & $P$-value Wilcoxon rank sum test \\
\hline & $(N=64)$ & $(N=88)$ & & \\
\hline Mean (SD) age (years) & $39.6(8.0)$ & $37.7(10.4)$ & 0.616 & 0.288 \\
\hline Mean (SD) weight (kg) & $66.2(9.5)$ & $58.8(13.4)$ & 0.116 & 0.092 \\
\hline Mean (SD) BMI (kg/m2) & $23.7(4.9)$ & $21.6(4.4)$ & 0.184 & 0.209 \\
\hline \multirow[t]{2}{*}{ Mean (SD) CD4 count (cells/uL) } & $561.7(504.5)$ & $338.8(302.7)$ & 0.228 & 0.144 \\
\hline & n (\%) & n (\%) & $P$-value Chi square & $P$-value Fisher \\
\hline Male sex & $4(12.5 \%)$ & $28(87.5 \%)$ & 0.701 & 0.728 \\
\hline Ethnicity & & & 0.404 & 0.381 \\
\hline Akan & $6(16.2 \%)$ & $31(83.8 \%)$ & & \\
\hline Ewe & $0(0.0 \%)$ & $15(100.0 \%)$ & & \\
\hline Ga & $1(12.5 \%)$ & $7(87.5 \%)$ & & \\
\hline Other & $2(9.5 \%)$ & $19(90.5 \%)$ & & \\
\hline WHO HIV stage & & & 0.265 & 0.174 \\
\hline $1 \& 2$ & $2(5.1 \%)$ & 37 (94.9 \%) & & \\
\hline $3 \& 4$ & $7(16.3 \%)$ & $36(83.7 \%)$ & & \\
\hline HBeAg positive & $0(0.0 \%)$ & $19(100.0 \%)$ & 0.083 & 0.110 \\
\hline HBeAb positive & $9(13.6 \%)$ & $57(86.4 \%)$ & 0.107 & 0.193 \\
\hline HBeAg/E Ab combination & & & 0.361 & 0.339 \\
\hline HBeAg positive/Ab negative & $0(0.0 \%)$ & $16(100.0 \%)$ & & \\
\hline HBeAg negative/Ab positive & $9(14.3 \%)$ & $54(85.7 \%)$ & & \\
\hline HBeAg negative/Ab negative & $0(0.0 \%)$ & $1(100.0 \%)$ & & \\
\hline HBeAg positive/Ab positive & $0(0.0 \%)$ & $3(100.0 \%)$ & & \\
\hline HBclgM positive & $0(0.0 \%)$ & $1(100.0 \%)$ & 0.726 & 1.000 \\
\hline Alanine aminotransferase & & & 0.622 & 0.731 \\
\hline Normal (5-40 U/L) & $6(12.2 \%)$ & $43(87.8 \%)$ & & \\
\hline Elevated $>$ ULN & $3(8.8 \%)$ & $31(91.2 \%)$ & & \\
\hline Aspartate aminotransferase & & & 0.320 & 0.473 \\
\hline Normal (5-50 U/L) & $7(13.5 \%)$ & $45(86.5 \%)$ & & \\
\hline Elevated > ULN & $2(6.5 \%)$ & $29(93.6 \%)$ & & \\
\hline Albumin & & & 0.945 & 1.000 \\
\hline Normal (36-50 g/L) & $4(11.1 \%)$ & $42(89.4 \%)$ & & \\
\hline Low $<$ LLN & $5(10.6 \%)$ & $19(54.3 \%)$ & & \\
\hline
\end{tabular}

$B M I$ body mass index

$\mathrm{HBeAg/Ab}$ Hepatitis B e Antigen/Antibody

HBclgM Hepatitis B core IgM

$U L N$ : upper limit of normal

LLN lower limit of normal

incomplete HBV DNA suppression has been shown to occur in $54 \%$ following 12 months of TDF-based ART [8].

A longer duration of TDF therapy is required for achievement of virologic response (HBV DNA $<20 \mathrm{IU} /$ $\mathrm{mL}$ ) in co-infected patients. Among $\mathrm{HBeAg}$-positive patients, $92 \%(n=67)$ had HBV DNA $<20 \mathrm{IU} / \mathrm{mL}$ after 5 years of treatment [19]. In HBeAg-negative patients, $100 \%(n=15)$ achieved undetectable HBV DNA in 4 years [19]. Similarly, after a median of 74.7 months,
$86.5 \%(n=111)$ of co-infected patients demonstrated a virologic response with HBV DNA $<60 \mathrm{IU} / \mathrm{mL}$ [20]. There was no difference between patients with or without 3TC [19]. Tenofovir-based ART therefore achieves high HBV DNA suppression $\sim 90 \%$ at 5 years without evidence of resistance in comparison to 3TC only ART [21].

In our study, HBV DNA was undetectable in 42.0 and $42.3 \%$ irrespective of whether TDF was included in the 
Table 4 Factors associated with detectable HBV DNA in multivariate model in all patients and antiretroviral treatment-experienced

\begin{tabular}{|c|c|c|c|c|c|c|}
\hline \multirow[t]{2}{*}{ Factor } & \multicolumn{3}{|l|}{ All patients } & \multicolumn{3}{|c|}{ ART-experienced } \\
\hline & Odds ratio & $95 \%$ Confidence Interval & $P$ value & Odds ratio & $95 \%$ Confidence Interval & $P$ value \\
\hline Sex (Male vs Female) & - & - & - & 2.1 & $1.0-4.2$ & 0.0320 \\
\hline ART (Naïve vs. Experienced) & 10.1 & $4.6-21.9$ & $<0.0001$ & - & - & - \\
\hline ALT (Elevated vs. Normal) & 3.7 & $1.8-7.9$ & 0.0006 & 4.8 & $2.1-12.1$ & 0.0001 \\
\hline ALB (low vs. normal) & - & - & - & 1.9 & $0.8-4.2$ & 0.1326 \\
\hline
\end{tabular}

$A R T$ anti-retroviral therapy

ALT serum Alanine aminotransferase

$A L B$ : serum albumin

regimen. The median duration on therapy and IQR for 3TC-only and $3 \mathrm{TC}+\mathrm{TDF}$ were 4.85 years IQR $(3.02-$ 7.16) and 4.87 years IQR (3.81-5.85) respectively. This suggests the influence of other factors in sub-optimal therapeutic response. Poor adherence is often considered as an important factor in patients with persistently detectable HBV DNA on nucleoside analogue therapy [20]. It is also possible that the $33(21.7 \%)$, treated patients with HBV DNA $>2000 \mathrm{IU} / \mathrm{mL}$ harbor $\mathrm{HBV}$ resistant mutants. After a median of 45 months of 3TC, HBV DNA was found to be undetectable $(<14 \mathrm{IU} / \mathrm{mL})$ in $49.1 \%(n=106)$ of co-infected patients in Kumasi, Ghana [22]. Among patients with detectable HBV DNA, $42.6 \%$ also had detectable HIV RNA [22]. Overall, $29.6 \%$ of patients harbored one or more 3TC resistance mutations comprising M204I or M24V in all cases [22].

In this study, HIV RNA was not determined. Its cross-sectional design also did not allow for a temporal assessment of the influence of study predictors such as pre-treatment HBV DNA, adherence on virologic response in treated patients. Furthermore, the small sample size of treatment naive patients limited the evaluation of predictors and detectable HBV DNA.

The serum aminotransferases are sensitive indicators of liver cell inflammation [23]. The most commonly measured are ALT and AST. In HBV-infection, high ALT levels $>30 \mathrm{IU} / \mathrm{L}$ in males and $19 \mathrm{IU} / \mathrm{L}$ in females, HBV DNA $>20,000 \mathrm{IU} / \mathrm{mL}$ can better differentiate between active chronic HBV patients from inactive chronic carriers [24]. However, an increase in serum ALT in co-infected patients may be the result of ART hepatotoxicity, drug resistance, immune reconstitution, drug withdrawal, antituberculous therapy and opportunistic or super-infections [21, 25]. In our study, an elevated ALT was significantly associated with viremia in HBV/HIV co-infected patients irrespective of treatment status. In comparison with HBeAg status, the relationship between serum ALT and viremia in treated patients persisted following multivariate analysis.

We found that males had higher baseline HBV DNA in comparison to females in naïve and ART-experienced patients. The reason is unclear, and will be in keeping with an increased liver-related mortality rate in men with HIV and HBsAg compared with those with only HBsAg (14.2/1000 compared with 0.8/1000) [26]. Reviews in Africa have shown that women are more likely to access and maintain follow up for HIV care [27, 28]. Additionally, in co-infected patients, women had higher intracellular trough concentrations of TDF in a pilot pharmacokinetic study [29]. This raises the possibility of gender differences in adherence or intracellular concentrations of the nucleoside reverse transcriptase inhibitors diphosphate or triphosphates, which would need evaluation in prospective studies.

\section{Conclusion}

Routine Hepatitis B screening is essential in the evaluation and management of HIV patients. Elevated HBV DNA level is associated with overall mortality in HBV/ HIV co-infected patients, especially during the period before development of AIDS [30], and it is essential to identify patients who have viremia for treatment intensification. Majority of ART-naive (89 \%) and $42 \%$ of ARTexperienced patients were found to have detectable HBV. An abnormal serum ALT was significantly associated with $\mathrm{HBV}$ viremia in HBV-HIV co-infected patients irrespective of treatment status. Baseline and on-treatment ALT may therefore be a useful non-invasive cost-effective predictor of HBV viremia in resource-constrained countries in subSaharan Africa where the infection is endemic thereby assisting in risk stratification of patients for liver-related complications. Serum ALT may serve as a useful tool on monitoring disease activity and treatment response in naïve and ART-experienced patients and could be used to prioritize when or which patients should get more costly viral load testing to aid decision about optimizing treatment.

\footnotetext{
Abbreviations

3TC: Lamivudine; ALB: serum albumin; ALT: serum alanine Aminotransferase; ART: Anti-retroviral therapy; AST: serum aspartate Aminotransferase; BMI: Body Mass Index; HBclgG: Hepatitis B-c-lgG; HBclgM: Hepatitis B-c-lgM;

HBeAb: Hepatitis B-e-Antibody; HBeAg: Hepatitis B-e-Antigen; HBsAg: Hepatitis B-surface Antigen; HBV: Hepatitis B; HCC: Hepatocellular carcinoma; HIV: Human Immunodeficiency Virus; IQR: Inter-quartile range; KBTH: Korle-Bu Teaching Hospital; TDF: Tenofovir; ULN: Upper limit of normal.
}

Competing interests

The authors declare that they have no competing interests. 


\section{Authors' contributions}

TNA, ML and AK contributed to conception and the study design, acquisition of data, analysis and interpretation of data, and drafting of the manuscript. TF contributed to conception and study design and review of the manuscript. FG and HY contributed to interpretation of data, drafting of the manuscript and review of manuscript. EK contributed to acquisition of data and review of manuscript. KWC, IB and AOA contributed to laboratory testing, acquisition of laboratory data and review of the manuscript. All authors read and approved the final manuscript.

\section{Acknowledgements}

We thank the patients for participation in this study. This study was funded by a 2012 International Developmental Grant from the Lifespan/Tufts/Brown CFAR (P30AI042853) and the Brown/Tufts AIDS International Training and Research Program (D43TW000237) to Drs. Archampong and Kwara. Additional support was provided by Brown University - University of Ghana partnership through a USAID/HED grant (Award \# AEG-A-00-05-00007). We wish to acknowledge MDS Lancet Laboratories, Ghana for performing HBV DNA on study participants. We are grateful for the support of Drs. Michael Stein and Annie Gjelsvik, Brown University, for their assistance in development of study design.

\section{Author details}

'Department of Medicine and Therapeutics, School of Medicine and Dentistry, College of Health Sciences, University of Ghana, Accra, Ghana. ${ }^{2}$ Korle-Bu Teaching Hospital, Accra, Ghana. ${ }^{3}$ Department of Microbiology, School of Biomedical and Allied Health Sciences, College of Health Sciences, University of Ghana, Accra, Ghana. "Warren Alpert Medical School of Brown University, Providence, RI, USA. ${ }^{5}$ The Miriam Hospital, Providence, RI, USA. ${ }^{6}$ Department of Biostatistics and Computational Biology, University of Rochester School of Medicine and Dentistry, Rochester, NY, USA.

Received: 21 July 2015 Accepted: 9 January 2016

Published online: 13 January 2016

\section{References}

1. World Health Organization Factsheet: Hepatitis B. http://www.who.int/ mediacentre/factsheets/fs204/en/. July 2015.

2. Puoti M, Airoldi M, Bruno R, Zanini B, Spinetti A, Pezzoli C, et al. Hepatitis B virus co-infection in human immunodeficiency virus-infected subjects. AIDS Rev. 2002;4(1):27-35.

3. Kellerman SE, Hanson DL, McNaghten AD, Fleming PL. Prevalence of chronic hepatitis $B$ and incidence of acute hepatitis $B$ infection in human immunodeficiency virus-infected subjects. J Infect Dis. 2003;188(4):571-7.

4. McGovern $\mathrm{BH}$. The epidemiology, natural history and prevention of hepatitis B: implications of HIV coinfection. Antivir Ther. 2007;12 Suppl 3:H3-13.

5. Thio CL, Seaberg EC, Skolasky Jr R, Phair J, Visscher B, Munoz A, et al. HIV-1, hepatitis B virus, and risk of liver-related mortality in the Multicenter Cohort Study (MACS). Lancet. 2002;360(9349):1921-6.

6. Iloeje UH, Yang HI, Su J, Jen CL, You SL, Chen CJ. Risk evaluation of viral load E, associated liver disease/cancer-in HBVSG: predicting cirrhosis risk based on the level of circulating hepatitis B viral load. Gastroenterology. 2006;130(3):678-86.

7. Thio CL. Hepatitis B and human immunodeficiency virus coinfection. Hepatology. 2009;49(5 Suppl):S138-145

8. Hafkin JS, Osborn MK, Localio AR, Amorosa VK, Kostman JR, Stern JJ, et al. Incidence and risk factors for incomplete HBV DNA suppression in HIV/HBVco-infected patients initiating tenofovir-based therapy. J Viral Hepat. 2014; 21(4):288-96.

9. Soriano V, Puoti M, Peters M, Benhamou Y, Sulkowski M, Zoulim F, et al. Care of HIV patients with chronic hepatitis B: updated recommendations from the HIV-Hepatitis B Virus International Panel. Aids. 2008;22(12):1399410.

10. Matthews GV, Seaberg EC, Avihingsanon A, Bowden S, Dore GJ, Lewin SR, et al. Patterns and causes of suboptimal response to tenofovir-based therapy in individuals coinfected with HIV and hepatitis B virus. Clin Infect Dis. 2013; 56(9):e87-94.

11. Blankson AWE, Gyasi RK, Adjei A, Tettey Y. Sero-prevalence of Hepatitis B and C viruses in cirrhosis of the liver in Accra, Ghana. Ghana Med J. 2005; 39(4):132-7.
12. Sagoe KW, Agyei AA, Ziga F, Lartey M, Adiku TK, Seshi M, et al. Prevalence and impact of hepatitis B and C virus co-infections in antiretroviral treatment naive patients with HIV infection at a major treatment center in Ghana. J Med Virol. 2012;84(1):6-10.

13. Geretti AM, Patel M, Sarfo FS, Chadwick D, Verheyen J, Fraune M, et al. Detection of highly prevalent hepatitis B virus coinfection among HIVseropositive persons in Ghana. J Clin Microbiol. 2010;48(9):3223-30.

14. Panel on Antiretroviral Guidelines for Adults and Adolescents. Guidelines for the use of antiretroviral agents in HIV-1-infected adults and adolescents. Edited by DHHS. 2012.

15. Knobel H, Alonso J, Casado JL, Collazos J, Gonzalez J, Ruiz I, et al. Validation of a simplified medication adherence questionnaire in a large cohort of HIVinfected patients: the GEEMA Study. Aids. 2002:16(4):605-13.

16. Breheny P, Huang J. Coordinate descent algorithms for nonconvex penalized regression, with applications to biological feature selection. Ann Appl Stat. 2011;5(1):232-53.

17. Fan J, Li R. Variable selection via nonconcave penalized likelihood and its oracle properties. J Am Stat Assoc. 2001;96(456):1348-60.

18. Lok AS, McMahon BJ. Chronic hepatitis B: update 2009. Hepatology. 2009; 50(3):661-2

19. de Vries-Sluijs TE, Reijnders JG, Hansen BE, Zaaijer HL, Prins JM, Pas SD, et al. Long-term therapy with tenofovir is effective for patients co-infected with human immunodeficiency virus and hepatitis B virus. Gastroenterology. 2010:139(6):1934-41.

20. Boyd A, Gozlan J, Maylin S, Delaugerre C, Peytavin G, Girard PM, et al. Persistent viremia in human immunodeficiency virus/hepatitis B coinfected patients undergoing long-term tenofovir: virological and clinical implications. Hepatology. 2014;60(2):497-507.

21. WHO Guidelines for prevention, care and treatment of persons with Chronic Hepatitis B (www.who.int). March 2015.

22. Stockdale AJ, Phillips RO, Beloukas A, Appiah LT, Chadwick D, Bhagani S, et al. Liver fibrosis by transient elastography and virologic outcomes after introduction of tenofovir in lamivudine-experienced adults with HIV and Hepatitis B virus coinfection in Ghana. Clin Infect Dis. 2015;61(6):883-91.

23. Ellis G, Goldberg DM, Spooner RJ, Ward AM. Serum enzyme tests in diseases of the liver and biliary tree. Am J Clin Pathol. 1978;70(2):248-58.

24. ljaz B, Ahmad W, Javed FT, Gull S, Hassan S. Revised cutoff values of ALT and HBV DNA level can better differentiate HBeAg (-) chronic inactive HBV patients from active carriers. Virol J. 2011;8:86.

25. Hoffmann CJ, Charalambous S, Thio CL, Martin DJ, Pemba L, Fielding KL, et al. Hepatotoxicity in an African antiretroviral therapy cohort: the effect of tuberculosis and hepatitis B. Aids. 2007:21(10):1301-8.

26. Colin JF, Cazals-Hatem D, Loriot MA, Martinot-Peignoux M, Pham BN, Auperin A, et al. Influence of human immunodeficiency virus infection on chronic hepatitis B in homosexual men. Hepatology. 1999;29(4):1306-10.

27. Muula AS, Ngulube TJ, Siziya S, Makupe CM, Umar E, Prozesky HW, et al. Gender distribution of adult patients on highly active antiretroviral therapy (HAART) in Southern Africa: a systematic review. BMC Public Health. 2007;7: 63

28. Charurat M, Oyegunle M, Benjamin R, Habib A, Eze E, Ele P, et al. Patient retention and adherence to antiretrovirals in a large antiretroviral therapy program in Nigeria: a longitudinal analysis for risk factors. PLoS One. 2010; 5(5):e10584.

29. Pruvost A, Negredo E, Theodoro F, Puig J, Levi M, Ayen R, et al. Pilot pharmacokinetic study of human immunodeficiency virus-infected patients receiving tenofovir disoproxil fumarate (TDF): investigation of systemic and intracellular interactions between TDF and abacavir, lamivudine, or lopinavir-ritonavir. Antimicrob Agents Chemother. 2009;53(5):1937-43.

30. Nikolopoulos GK, Paraskevis D, Psichogiou M, Hatzakis A: HBV-DNA levels predict overall mortality in HIV/HBV coinfected individuals. J Med Virol 2016; 88(3):466-473. 